\title{
Proteomic Analysis of Cerebrospinal Fluid in Alzheimer's Disease: Wanted Dead or Alive
}

\author{
Zita Oláh ${ }^{\mathrm{a}, *}$, János Kálmán ${ }^{\mathrm{a}}$, Melinda E. Tóth ${ }^{\mathrm{b}}$, Ágnes Zvara ${ }^{\mathrm{c}}$, Miklós Sántha $^{\mathrm{b}}$, Eszter Ivitz ${ }^{\mathrm{a}}$, \\ Zoltán Janka ${ }^{\mathrm{a}}$ and Magdolna Pákáski ${ }^{\mathrm{a}}$ \\ ${ }^{a}$ Department of Psychiatry, Faculty of Medicine, University of Szeged, Szeged, Hungary \\ ${ }^{\mathrm{b}}$ Laboratory of Animal Genetics and Molecular Neurobiology, Institute of Biochemistry, Biological Research Centre, \\ Szeged, Hungary \\ ${ }^{\mathrm{c}}$ Laboratory of Functional Genomics, Biological Research Centre, Szeged, Hungary
}

Handling Associate Editor: Inga Zerr

Accepted 30 October 2014

\begin{abstract}
Clinical diagnosis of Alzheimer's disease (AD) relying on symptomatic features has a low specificity, emphasizing the importance of the pragmatic use of neurochemical biomarkers. The most advanced and reliable markers are amyloid- $\beta$ (A $\left.\beta_{42}\right)$, total tau (t-tau), and phosphorylated tau (p-tau) in cerebrospinal fluid (CSF) with relatively high levels of sensitivity, specificity, and diagnostic accuracy. Recent advances within the field of proteomics offer the potential to search for novel biomarkers in CSF by using modern methods, such as microarrays. The purpose of this study was to identify pathognostic proteins in CSF obtained from patients whose clinical AD diagnosis was confirmed by the "core" biomarkers. CSF samples were obtained from $25 \mathrm{AD}$ patients and 25 control individuals. The levels of $\mathrm{A} \beta_{42}$, t-tau, and p-tau were measured by ELISA. In the microarray experiments, ultrasensitive slides representing of 653 antigens were used. Apolipoprotein E genotyping was also determined. A decrease of seven CSF proteins in AD were found, four of them (POLG, MGMT, parkin, and ApoD) have a protective function against neuronal death, while the remaining three proteins (PAR-4, granzyme B, Cdk5) trigger multiple pathways facilitating neuronal cell death. Since these proteins from CSF samples could not be identified by western blot, their decreased levels in AD patients were not verified. Our results provide new information of pathognostic importance of POLG and granzyme B in AD. Although the function of MGMT, parkin, ApoD, PAR-4, and Cdk5 was previously known in AD, the findings presented here provide novel evidence of the significance of CSF analysis in the mapping of the AD pathomechanism.
\end{abstract}

Keywords: Alzheimer's disease, antibody microarray, ApoD, apoptosis, Cdk5, cerebrospinal fluid, granzyme B, MGMT, PAR-4, parkin, POLG

\section{INTRODUCTION}

Alzheimer's disease (AD) is a neurodegenerative disorder characterized by the accumulation of amyloid- $\beta(\mathrm{A} \beta)$ and hyperphosphorylated tau (p-tau) protein with consequential neuronal loss, neuroinflammation [1], and mitochondrial impairment [2, 3]. The clinical diagnosis of AD during life is difficult, although neurochemical markers are gaining greater importance in clinical routine. Biomarkers may be

${ }^{*}$ Correspondence to: Zita Oláh, Department of Psychiatry, Faculty of Medicine, University of Szeged, 6 Semmelweis street, Szeged H-6724, Hungary. Tel.: +36 625468 51; E-mail: olah.zita.87@gmail.com. useful not only in establishing the precise diagnosis or differentiating $\mathrm{AD}$ from other dementias, but in predicting the prognosis, as well [4]. Relating to the amyloid-cascade and the tau hypotheses [5], the measurements of $A \beta_{42}$, total tau (t-tau), and p-tau from the cerebrospinal fluid (CSF) by ELISA are the most commonly used diagnostic methods. The sensitivity of these measurements is about $85 \%$, while their specificity is even higher, about $95 \%$ [6]. However their positive predictive value is much lower, especially in prodromal $\mathrm{AD}$, which has increasing diagnostic importance due to the advantages of early interventions. Although ELISA procedures are well adapted and have been optimized to measure samples in normal and 
pathological range [7], 34\% of non-AD type demented patients have an AD biomarker profile and 36\% of cognitively normal subjects have a pathological AD CSF profile [8].

Currently, there is no other neurochemical diagnostic method which could detect changes of specific molecules related to the pathomechanism of $\mathrm{AD}$, such as neuronal degeneration, neuroinflammation, oxidative stress, or mitochondrial impairment [9]. Additionally, up to now, there are no data obtained from those $\mathrm{AD}$ patients who were diagnosed by not only the clinical routine National Institute of Neurological and Communicative Disorders and Stroke/Alzheimer's Disease and Related Disorders Association (NINCDS/ADRDA) criteria [10, 11], but also by using approved CSF biomarkers.

Therefore the aim of our study was to identify changes of proteins related to $\mathrm{AD}$ pathomechanism in CSF obtained from patients whose clinical AD diagnosis was confirmed by $\mathrm{A} \beta_{42}$, $\mathrm{t}$-tau, and p-tau ELISA. In addition, the relationship between apolipoprotein E (ApoE) genotype and proteomic changes was also examined.

\section{MATERIALS AND METHODS}

\section{Subjects}

The AD group consisted of 25 patients ( 9 men and 16 women), the average age and standard deviation (SD) was $72.04 \pm 5.03$ years. The clinical diagnosis of $\mathrm{AD}$ was validated by initial evaluation through careful history taking (personal and family histories), neurological and psychiatric examinations, together with the assessment of psychometric tests to confirm cognitive impairment. Furthermore, a brain CT scan or MRI was conducted in each case, and in some cases SPECT was done to exclude other neurological diseases. Routine laboratory work-up including determination of thyroid hormone levels was also carried out. All participants fulfilled criteria outlined in the Fourth edition of the Diagnostic and Statistical Manual of Mental Disorders (DSM-IV, 1994) [12] and had probable AD according to the criteria of NINCDS-ADRDA [10, 11].

The cognitive evaluation of AD patients was carried out using the AD Assessment Scale - Cognitive Subscale [13, 14], the Mini-Mental State Exam (MMSE) $[15,16]$, and the Clock Drawing Test [17]. Mood was scored using Beck Depression Inventory [18]. The average score and SD of MMSE of AD patients was $15.16 \pm 2.55$.
Control subjects without any subjective symptoms of cognitive dysfunction were recruited from the Neurology Department of our University. A thorough neurological examination, routine lab tests, and brain CT or MRI were also conducted on the control participants. The control group consisted of 25 ageand gender-matched (9 men, 16 women) individuals. The average age and SD of the control group was $74.52 \pm 2.48$ years.

Ethical permission for lumbar puncture was obtained from the Ethics Committee of the University of Szeged, Hungary, where written informed consent had been required for all probands (permit No. 184/2012).

\section{CSF collection}

CSF samples used in this study were obtained from patients undergoing a lumbar puncture in the L4-L5 vertebral interspace. All the interventions were performed in the morning, between 9.00 a.m. - 11.00 a.m. Twelve $\mathrm{ml}$ of CSF were collected into polypropylene tubes from each patient and control individual. CSF samples were transferred to the laboratory on $-20^{\circ} \mathrm{C}$ within 1-2 hours. Each CSF sample was aliquoted and frozen immediately to minimize any metabolic damage. Routine laboratory investigation, such as protein amount and cell count were determined, the remainder of samples were stored at $-80^{\circ} \mathrm{C}$ until further analysis. All measurements were done within 1-3 month after sample collection.

\section{$A \beta_{42}$ and tau enzyme-linked immunosorbent assay}

CSF samples were analyzed using ELISA $\left(\mathrm{GenoID}^{\circledR}\right.$, INNOTEST hTAU, INNOTEST $\beta$ Amyloid, INNOTEST Phospho-Tau) according to the manufacturer's instructions. Internationally accepted $\mathrm{AD}$ specific cutoff points were used. $\mathrm{AD}$ specific values are $A \beta_{42}<500 \mathrm{pg} / \mathrm{mL}, \mathrm{t}$-tau $>600 \mathrm{pg} / \mathrm{mL}$, and $\mathrm{p}$-tau $>60 \mathrm{pg} / \mathrm{mL}$. The normal (non-AD specific) values (mean $\pm \mathrm{SD}$ ) are $\mathrm{A} \beta_{42} 794 \pm 20 \mathrm{pg} / \mathrm{mL}$, t-tau $341 \pm 171 \mathrm{pg} / \mathrm{mL}$, and p-tau $23 \pm 2 \mathrm{pg} / \mathrm{mL}$ [6].

\section{ApoE polymerase chain reaction and restriction fragment length polymorphism}

ApoE genotypes were determined with a previously described method [19]. Genomic DNA was extracted from peripheral blood leukocytes using a kit (Roche Applied Bioscience LTD), according to the manufacturer's instructions. Polymerase chain reaction (PCR) 
and restriction fragment length polymorphism (RFLP) were used to analyze ApoE alleles.

\section{Peptide microarray analysis}

Master Antibody Microarray (Spring BioScience ${ }^{\circledR}$, Cat. \# AMS-700) was used to perform antibody array studies, according to the manufacturer's instructions. The specific antibodies were covalently immobilized on glass surface coated with 3D polymer materials to ensure high binding efficiency and specificity. Each slide was printed with 656 unique antibodies, positive and negative controls in duplicate. Two replicates were used to minimize errors on each microarrays.

Pooled samples of $5 \mathrm{AD}$ patients or 5 control patients were analyzed on the 5 antibody arrays. The concentration of native CSF proteins was measured with bicinchoninic acid before pooling them to determine the concentrations of the single samples. First, $2.7 \mathrm{mg}$ of proteins of pooled CSF were precipitated overnight with acetone $\left(4: 1\right.$; acetone:CSF) at $-20^{\circ} \mathrm{C}$ and then centrifuged at $14000 \times \mathrm{g}$ for $15 \mathrm{~min}$ at $4^{\circ} \mathrm{C}$. To remove salts, the supernatant was discharged and the pellet was resuspended in $500 \mu \mathrm{l}-20^{\circ} \mathrm{C} 90 \%$ acetone. It was centrifuged at $14000 \times \mathrm{g}$ for $5 \mathrm{~min}$ at $4{ }^{\circ} \mathrm{C}$. The resulted protein pellet was resuspended in $50 \mu \mathrm{l}$ labelling buffer of the Antibody Microarray Detection Kit (Spring BioScience ${ }^{\circledR}$, Cat. \#AMD-001). The concentration of resuspended samples was measured with NanoDrop-2000. Protein samples were then biotinylated and conjugated to the antibody array. To visualize the coupled proteins Cy3-Streptavidin was used (GE Healthcare, Cat. \# PA43001). Fluorescent staining of 653 proteins on peptide microarrays was measured using an Agilent scanner. Image analysis and normalization were done by the Genepix Pro 6.0 software.

Each spot was defined by automatic positioning of a grid given by the manufacturer. The median values of feature and local background pixel intensities were determined. Background corrected intensity data were filtered for flagged spots and weak signals. Technical replicates on the same array were averaged. Data were excluded in cases where technical replicates were significantly different or only one of the replicate had shown change in intensity. Median normalization was performed. Ratio of $\mathrm{AD}$ values and control values was used to determine alterations. A ratio below 0.6 meant a decrease, while a ratio above 1.8 meant increase of the given protein level.

\section{Western blot analysis}

To confirm our previous results, $20 \mu \mathrm{g}$ or $40 \mu \mathrm{g}$ of protein was used and separated on $12 \%$ SDS- polyacrylamide gel and electroblotted (100V/ $45 \mathrm{~min})$ onto PVDF or nitrocellulose membranes. The samples were blocked in a solution of $0.2 \mathrm{M}$ Tris-buffered saline containing $0.02 \%$ Tween 20 (TBST) supplemented with $5 \%$ non-fat milk for $1 \mathrm{~h}$. The membranes were then incubated overnight with rabbit polyclonal MGMT, PAR-4, and granzyme B (Bioss INC.; cat\# bs-1196R; bs-1351R; bs-1002R) All of them was tested at different dilutions, as follows 1:500; 1:1000; 1:2000. The next day, after five washes with TBST, horseradish-peroxidase-labelled anti-rabbit IgG (Jackson Immunoresearch, West Grove, PA, USA; 1:1000) secondary antibody was applied for $90 \mathrm{~min}$. The membranes were subsequently washed five times with TBST, and incubated with the Supersignal ${ }^{\circledR}$ West Pico Chemiluminescent Substrate (Pierce, Rockford, IL, USA) and exposed to KODAK autography film.

\section{Statistical analysis}

Statistical analyses were performed by IBM SPSS statistics 20 software. Student's $t$-test was used due to the normal distribution of the values. The level of significance was ${ }^{* * *} p \leq 0.001$.

\section{RESULTS}

To confirm the clinical diagnoses of $\mathrm{AD}$, the levels of $A \beta_{42}$, t-tau, and p-tau proteins of the CSF samples were measured using ELISA. A $\beta_{42}$, t-tau, and p-tau levels of control probands $(n=25)$ were in internationally accepted normal range $\left(\mathrm{A} \beta_{42} 666.0 \pm 270.1\right.$ $\mathrm{pg} / \mathrm{mL}$; t-tau $270.1 \pm 83.9 \mathrm{pg} / \mathrm{mL}$; p-tau $60.2 \pm 17.5$ $\mathrm{pg} / \mathrm{mL})$. We observed significant decrease in $A \beta_{42}$ levels $(p=0.000117)$, and significant increase in t-tau $(p=0.000008)$, and $\mathrm{p}$-tau $(p=0.000544)$ levels in the AD group compared with control probands (Fig. 1).

Based on the PCR fragment analysis, 9 of the 25 $\mathrm{AD}$ patients were heterozygous for ApoE4 and ApoE3 alleles (Table 1). Only 1 patient was heterozygous for ApoE2 and ApoE4 allele (Table 1). The remaining 15 patients were homozygous for ApoE3 allele (Table 1).

Comparing the AD and control samples based on complex analysis of pixel intensity, we found reduction in the cases of 7 proteins in 4 of the 5 pairs. Fig. 2 demonstrates representative original array scans from two AD pooled CSF samples with their matched control ones. The proteins with decreased levels in AD CSF were the following: DNA polymerase gamma (POLG) (Table 2; Fig. 3), methylated-DNA-proteincysteine methyltransferase (MGMT) (Table 2; Fig. 3), parkin (Table 2; Fig. 3), apolipoprotein D (ApoD) 


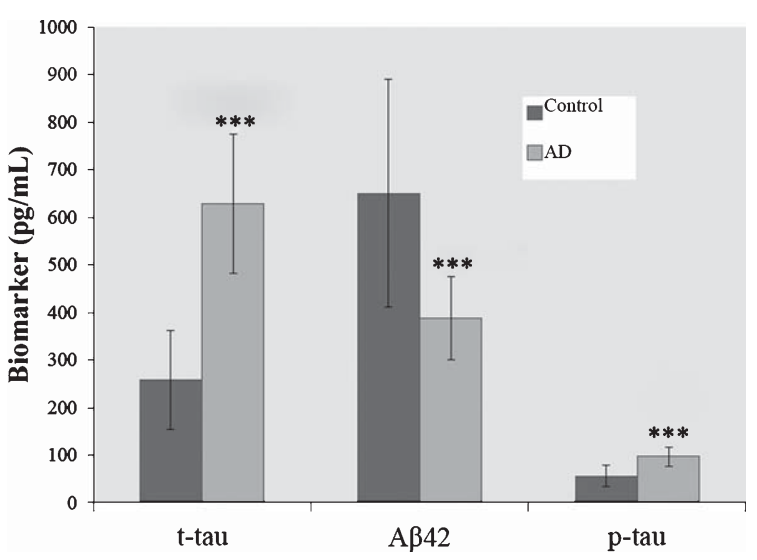

Fig. 1. $A \beta_{42}$, t-tau, and p-tau levels in CSF of AD patients and control probands were measured by Innogenetics and Invitrogen ELISA kits. The columns mean the averages of $A \beta_{42}$, t-tau, and p-tau levels, the bars indicate the standard deviation $\left({ }^{* * *} p \leq 0.001\right)$.

Table 1

Distribution of ApoE alleles in $25 \mathrm{AD}$ patients involved in the study

\begin{tabular}{ccccccc}
\hline & $2 / 2$ & $2 / 3$ & $2 / 4$ & $3 / 3$ & $3 / 4$ & $4 / 4$ \\
\hline ApoE alleles & 0 & 0 & 1 & 15 & 9 & 0 \\
\hline
\end{tabular}

One of the seven proteins found in decreased level in CSF samples of AD patients is POLG-critical for the synthesis, replication, and repair of mitochondrial DNA (mtDNA) - which has not been studied in either CSF or in brain tissue of patients with AD (Table 2). Our study was the first to recognize the reduced levels of POLG in CSF samples from AD patients. The relationship between POLG and the pathomechanism of $\mathrm{AD}$ has been suggested based on a detailed morphological mtDNA and genetic study of the brains of two siblings with progressive cognitive decline, AD pathology, POLG mutation, and ApoE4/4 genotype [22]. Our results are consistent with the findings of Podlesniy et al. [23], who found reduced mtDNA in CSF of patients with sporadic AD. Since abnormal function of POLG leads to cell death cascade via mitochondrial dysfunction and oxidative stress, these previous results and our data led us to conclude that the decreased levels of POLG in CSF from AD patients may reflect the mitochondrial dysfunction characteristic of this disease (Fig. 4).

MGMT is a specific repair protein that removes the alkyl group from an important site of DNA alkylation (Table 2; Fig. 4). So far only one study has been performed to measure the activity of MGMT in lymphocyte preparations from $\mathrm{AD}$ patients and control subjects which did not reveal any significant differences [24]. In contrast to these previous data, our results are the first to show reduced levels of MGMT in the CSF of AD patients. The apparent discrepancy between the earlier findings and our results can be explained by the difference in the used samples and techniques. Since, in the case of AD, changes in CSF are more relevant than those of the peripheral lymphocytes, a potential relation between the reduction of MGMT and AD pathomechanism can be suggested.

Parkin so far has not been investigated in similar human ex vivo CSF measurements (Table 2). Parkin is an ubiquitin E3 ligase involved in proteasomal degradation of misfolded proteins (Fig. 4) [25]. Parkin ubiquitinates intracellular $\mathrm{A} \beta$ in vivo and stimulates its removal via the proteasome or the autophagy-lysosome system [26]. Decreased parkin solubility was detected in postmortem $\mathrm{AD}$ cortex [27]. Overexpression of parkin in double or triple transgenic animal models of AD restored activity-dependent synaptic plasticity, rescued behavioral abnormalities, down-regulated A $\beta P P$ expression, reversed the effects of AD genes on inflammation and brain atrophy, suggesting that parkin could be a promising target for AD therapy [28, 29]. Our data provide further evidence of the role of parkin in the pathomechanism of $\mathrm{AD}$, and we suggest that its 



$\begin{array}{ll}\text { Alzheimer's } & \text { Alzheimer's } \\ \text { disease } 2 \mathrm{~A} & \text { disease } 2 \mathrm{~B}\end{array}$

Control 2A

Control 2B

Fig. 2. Photographs of representative pseudo-colored images of protein microarrays from Alzheimer's disease and control cerebrospinal fluid samples. The software colored the spots in order to visualize the level of intensity. Blue means the weakest signal intensities, accordingly. On each slide blocks are duplicated (Alzheimer's disease 1A and 1B; control 1A and 1B, Alzheimer's disease 2A and 2B; control 2A and 2B).

Table 2

Lists of proteins showing decreased level in CSF of AD patients

\begin{tabular}{lccl}
\hline Name & $\begin{array}{l}\text { Ratio } \pm \text { S.E.M. of AD and control } \\
\text { optical intensities of CSF proteins }\end{array}$ & $\begin{array}{c}\text { Molecular } \\
\text { weight }(\mathrm{kDa})\end{array}$ & $\begin{array}{l}\text { Function of } \\
\text { proteins }\end{array}$ \\
\hline POLG & $0.51 \pm 0.19$ & 139.6 & $\bullet$ replication of mitochondrial DNA \\
MGMT & $0.56 \pm 0.11$ & 21.6 & $\bullet$ mitochondrial functions \\
Parkin & $0.59 \pm 0.1$ & 51.6 & $\bullet$ DNA protection \\
ApoD & $0.62 \pm 0.17$ & 21.3 & $\bullet$ protein catabolism \\
PAR-4 & $0.6 \pm 0.08$ & 36.6 & $\bullet$ transport processes \\
Granzyme B & $0.37 \pm 0.24$ & 27.7 & $\bullet$ apoptosis \\
CDK5 & $0.45 \pm 0.09$ & 33.3 & $\bullet$ regulation of cell cycle \\
& & & $\bullet$ apoptosis
\end{tabular}

The numbers represent the ratio of pixel intensities derived from 5 control and 5 Alzheimer's disease independent microarrays. One microarray sample was a pooled construction of 5 individual CSF samples derived from control or Alzheimer's disease groups, respectively. Molecular weight and function of the seven proteins are also presented. AD, Alzheimer's disease; POLG, DNA polymerase gamma; MGMT, methylated-DNA-protein-cysteine methyltransferase; ApoD, apolipoprotein D; PAR-4, protein kinase C apoptosis WT1 regulator protein; Cdk5, cyclin-dependent kinase 5; S.E.M., standard error of mean; CSF, cerebrospinal fluid. 

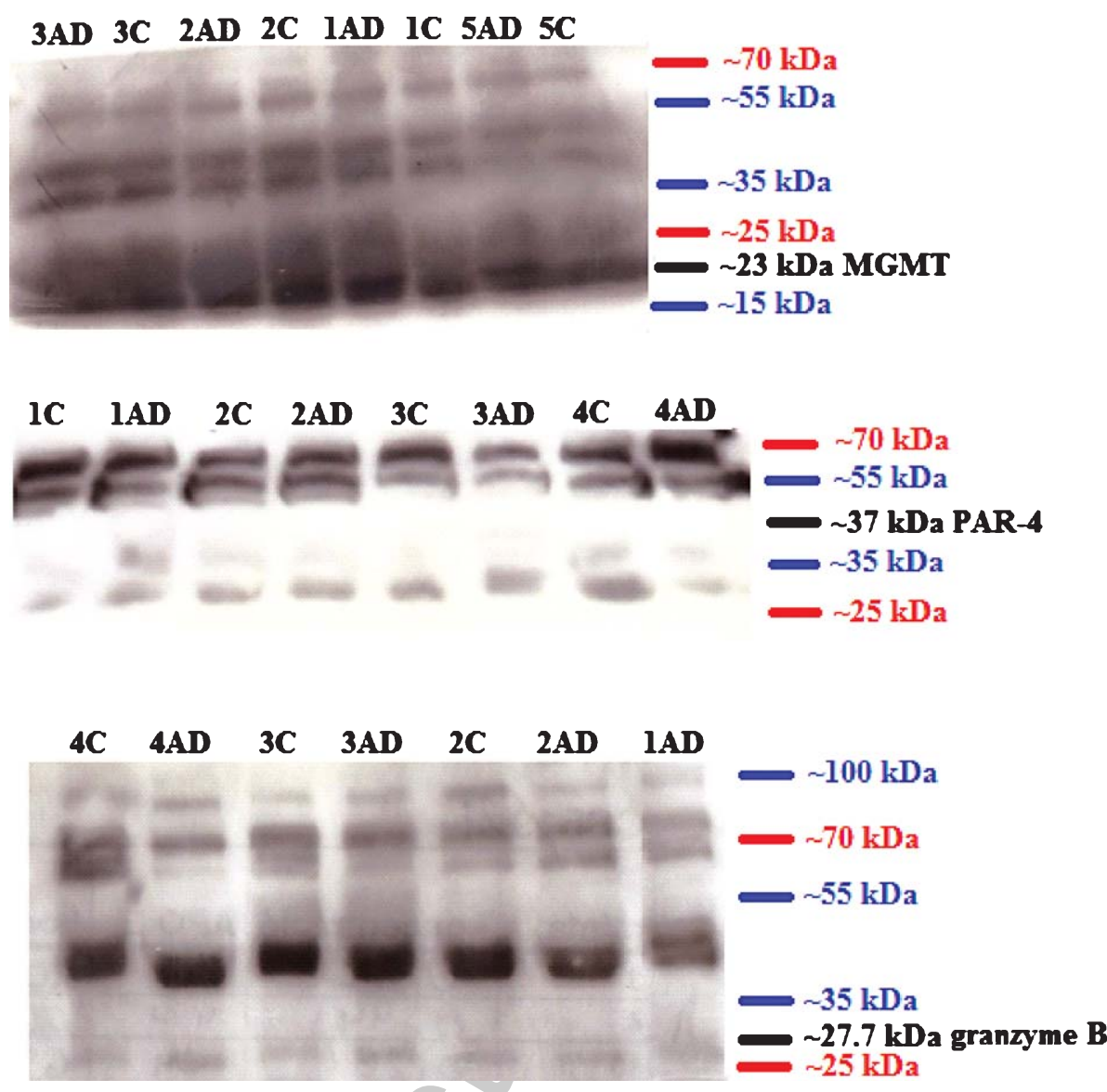

Fig. 3. Representative blot images from Alzheimer's disease and control cerebrospinal fluid samples. There were no signals on $23 \mathrm{kDa}$ (MGMT), on $37 \mathrm{kDa}$ (PAR-4), and on $27.7 \mathrm{kDa}$ (granzyme B). MGMT, methylated-DNA-protein-cysteine methyltransferase; PAR-4, protein kinase C apoptosis WT1 regulator protein; 1C-4C, control samples; 1AD-4AD, Alzheimer's disease samples

decreased level in the CSF may be the consequence of a compensatory intraneuronal parkin accumulation with $\mathrm{A} \beta$ and p-tau.

ApoD, a member of the lipocalin superfamily of lipid transport proteins, has been previously associated with AD (Table 2). However, its exact role is unclear. Upregulation of ApoD expression has been detected in the hippocampus or frontal cortex [30-32], and increased ApoD concentrations were also demonstrated in the hippocampus and in CSF of AD patients [33]. In contrast to this data measured by immunoblot and radioimmunometric assay, the peptide microarray analysis in our experimental setting showed a reduction of ApoD levels in the CSF of AD patients (Fig. 4). These various results can be explained with not only the different techniques used by the cited authors and us, but the different ApoE genotypes between the two AD populations. Terrisse et al. found correlation between the inheritance of ApoE4 allele and increased ApoD concentrations in a dose dependent manner in CSF of $\mathrm{AD}$ patients [33]. ApoE genotyping of our $\mathrm{AD}$ patients verified the presence of the ApoE4 allele in 10:50 ratio, which is considerably lower than the 24:60 ApoE4 allele ratio in the study of Terrisse et al. [33]. The relatively low number of ApoE4 allele in the investigated $\mathrm{AD}$ population may also explain the lack of any correlation between the found reduction of other proteins in CSF and ApoE genotyping.

PAR-4, a mediator of neuronal degeneration associated with AD (Table 2) [34, 35], has also not been tested yet in CSF of AD patients. Earlier, the levels of PAR-4 mRNA and protein were found to be increased in tissue from vulnerable brain regions of $\mathrm{AD}$ patients compared to age-matched control patients [34,35]. The present study reveals for the first time the decreased levels of PAR-4 in CSF of AD patients. Theoretically, PAR-4 may accumulate in AD brain causing a low level in CSF similar to $A \beta$, but its verification needs 


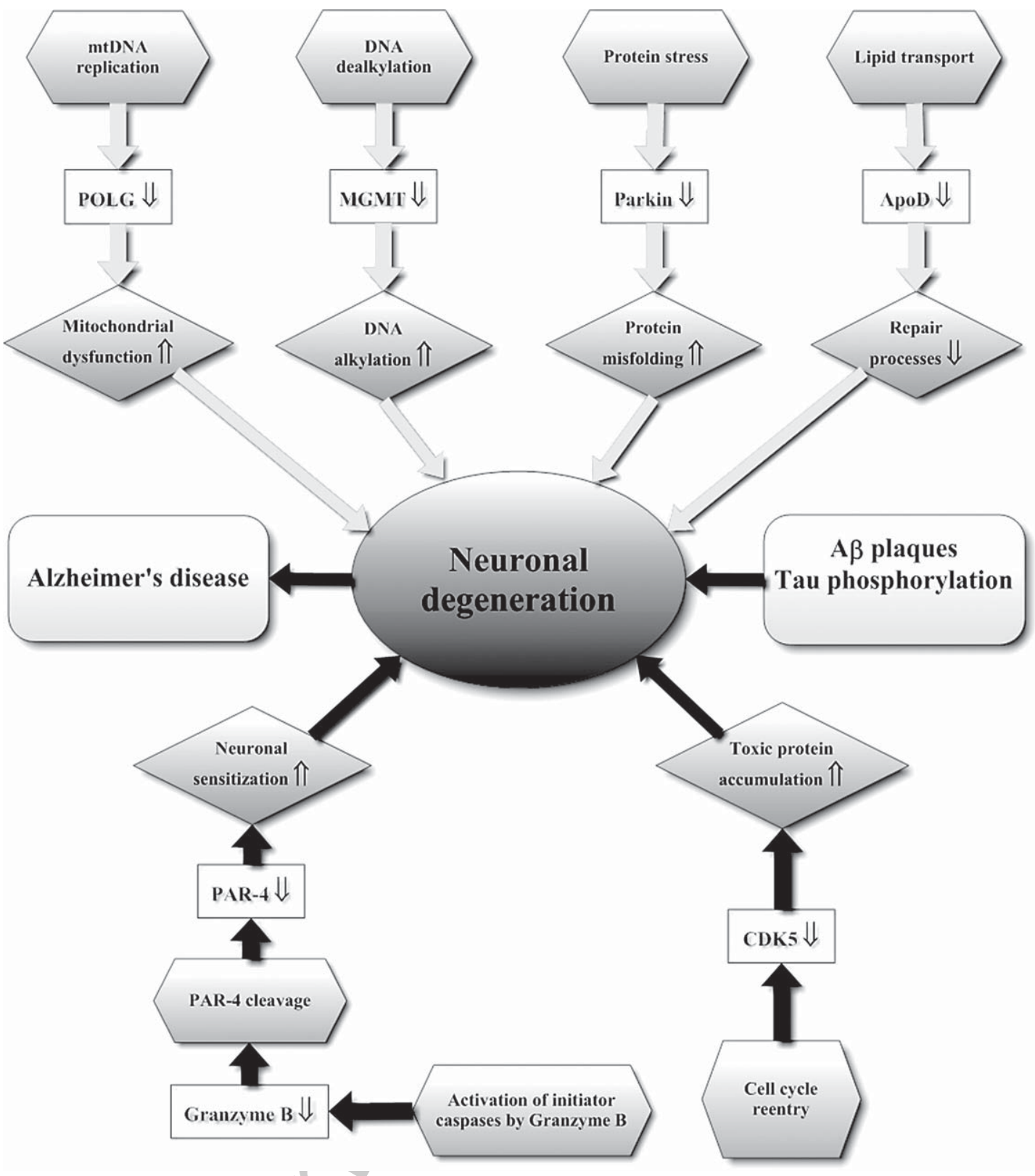

Fig. 4. Scheme how the proteins with reduced levels in AD CSF are involved in the pathomechanism of this disease. MGMT, parkin, POLG, and ApoD may have protective roles against neuronal degeneration; this is shown by the light grey arrows. PAR-4, granzyme B, and Cdk5 have roles in mediating neuronal cell death, which is presented by the dark grey arrows. POLG, DNA polymerase gamma; MGMT, methylated-DNAprotein-cysteine methyltransferase; ApoD, apolipoprotein D; PAR-4, protein kinase C apoptosis WT1 regulator protein; Cdk5, cyclin-dependent kinase 5; CSF, cerebrospinal fluid; AD, Alzheimer's disease.

further experiments. With regards to the function of PAR-4 (Fig. 4), it was initially identified to be associated with aberrant $A \beta$ production due to its direct involvement in regulation of the $\beta$-secretase (BACE1) activation [36]. Additionally, a novel mechanism of glial apoptosis induction by PAR-4-enriched exosomes was recently reported, which may critically contribute to $\mathrm{AD}$ [37].

PAR-4 is a substrate of caspase during apoptosis, and this activation of caspases appears to be mediated by granzyme B (Table 2; Fig. 4) [38, 39]. Interestingly, not only the levels of PAR-4 but also those of 
granzyme B are decreased in CSF obtained from AD patients compared to the control group. Despite the fact that granzyme B is another important regulator of apoptosis [39, 40], and has been investigated in inflammatory mediated neurodegenerative disorders [41], its potential role in AD has not been examined. The explanation of reduced granzyme $\mathrm{B}$ levels in CSF may be that granzyme $\mathrm{B}$ is able to enter into the target neurons inducing apoptosis of them [42], therefore its extracellular concentration may be reduced. The specificity of the reduced levels of granzyme B in CSF also requires further examinations.

Another protein which decreased in CSF obtained from AD patients was Cdk5 (Table 2). This multifunctional enzyme triggers a cascade of pathways, contributing to all hallmarks of $\mathrm{AD}$ : neurotoxic $\mathrm{A} \beta$ and neurofibrillary tangles formation, apoptosis, and neuronal death (Fig. 4) [43-46]. Normally, Cdk5 activity is tightly regulated in the nervous system by the neuronspecific, cyclin-related molecules p35 and p39. This regulation of $\mathrm{Cdk} 5$ is disrupted in $\mathrm{AD}$, since high intracellular $\mathrm{Ca}^{++}$activates calpain-mediated cleavage of p35 to p25, forming a more stable Cdk5/p25 complex, causing aberrant hyperphosphorylation of tau and neurofilament proteins, and inducing neuronal cell death [47]. Cdk5 also plays an important role in regulating the reorganization of the cytoskeleton [48]. Cdk5 modulates the signaling of actin dynamics regulated by cofilin [49], the regulatory system possibly involved in stress-related biochemical events in $\mathrm{AD}$ [50]. The earlier postmortem data relating to brain levels of $\mathrm{Cdk} 5$ are contradictory. Recent studies show that $\mathrm{Cdk} 5$ protein levels in postmortem brains were significantly elevated in $\mathrm{AD}$ when compared to non-cognitively impaired controls, and that Cdk5 levels significantly correlated to BACE1 levels [51]. On the contrary, other publications have reported that $\mathrm{Cdk} 5$ levels appear unchanged $[43,52]$. These earlier reports and our own investigation lead us to conclude that $\mathrm{Cdk} 5$ may play a crucial role in $\mathrm{AD}$ pathomechanism. However, its changes in opposite directions between the brain and CSF cannot be explained and require further investigation.

We should emphasize that our results also have limitations. The microarray assay we used is highly sensitive [53] according to the references of the manufacturer of the kit, therefore it is able to detect even little alterations in the protein concentrations which are undetectable in high amounts of proteins with other widespread molecular methods, such as western blot $[54,55]$. Similarly to our results, the attempts for validation of antibody microarray results were unsuccessful by either ELISA or western blot $[54,55]$. The failure of the validation can be explained by the different amounts of the tested proteins in the microarray and the western blot experiments. Regarding the protein quantities, $2.7 \mathrm{mg}$ total CSF protein was analyzed in the peptide microarray experiment. On the other hand, an almost 70 times smaller amount, only $40 \mu \mathrm{g}$ total, of CSF protein was loaded on the gels in the western blot experiment due to the limitations of this method. One potential solution for this problem could be to concentrate the CSF samples to get stronger signals on the blots, but this approach may cause biased results due to the disproportional precipitation and loss of certain subfractions of proteins [56]. On the other hand, western blot analysis is a semi-quantitative method, and the difference within band size and density should be interpreted carefully, because the linearity of the staining may be incorrect especially in the case of low amount of proteins (below $5 \mu \mathrm{g}$ ) [57]. The special proteome of CSF is $70-80 \%$ of the immunoglobulin and albumin. Furthermore, these may bind other proteins. On the other hand, CSF has a low protein concentration, but high salt content, and until now the highest efficiency of protein precipitation is about 70-75\% [56, 59]. Another characteristic of CSF is the high intra- and interpersonal proteome variability. In order to reduce the effects of this phenomenon, pooled samples were used in our experimental design [59]. These limitations make CSF investigation one of the most challenging fields of biomarker research in $\mathrm{AD}$ and other neurodegenerative disorders.

All subjects included in our control group are patients with different diseases (such as headache, epilepsy) with the possibility of having impact on CSF proteomes. On the basis of ethical considerations, there is no possibility to gain CSF without any diagnostic reason to find age- and gender-matched healthy control probands. There was also no possibility to determine the ApoE genotypes of this control group.

In conclusion, we are the first to provide data by protein microarray approach in CSF samples from neurochemically verified AD patients. We found a decrease of seven proteins (POLG, MGMT, parkin, ApoD, PAR-4, granzyme B, Cdk5) in AD CSF compared to CSF of non-demented control probands. Among these seven proteins, the pathognostic importance of POLG and granzyme B has not been previously tested in AD. The function of all of these proteins is associated with the pathomechanism of neuronal degeneration. Interestingly, the reduced levels in CSF were identified not only in the case of those proteins which play protective roles against the neuronal degeneration (POLG, MGMT, parkin, and ApoD), but 
in the case of those proteins (PAR-4, granzyme B, and $\mathrm{Cdk} 5$ ) which trigger multiple pathways facilitating neuronal cell death. The possible cause of the reduction of these destructive proteins can be explained by their pathological accumulations within the brain, although further analysis is needed to clarify the exact mechanism.

\section{ACKNOWLEDGMENTS}

This research was supported by the European Union and the State of Hungary, co-financed by the European Social Fund in the framework of TÁMOP 4.2.4. A/2-11-1-2012-0001 'National Excellence Program'. This study was supported by grants from OTKA (83667), the Hungarian Ministry of Education and Culture (TÁMOP -4.2.2.A-11/1/KONV-2012-0052, Hungarian Brain Research Program - Grant No. KTIA_13_NAP-A-II/16.

The authors thank Örsike Fazekas, MD, for grammatically editing the manuscript.

Authors' disclosures available online (http://www.jalz.com/disclosures/view.php?id=2616).

\section{REFERENCES}

[1] Niranjan R (2013) Molecular basis of etiological implications in Alzheimer's Disease: Focus on neuroinflammation. $\mathrm{Mol}$ Neurobiol 48, 412-428.

[2] Nakamura T, Lipton SA (2010) Redox regulation of mitochondrial fission, protein misfolding, synaptic damage, and neuronal cell death: Potential implications for Alzheimer's and Parkinson's diseases. Apoptosis 15, 1354-1363.

[3] Morán M, Moreno-Lastres D, Marín-Buera L, Arenas J, Martín MA, Ugalde C (2012) Mitochondrial respiratory chain dysfunction: Implications in neurodegeneration. Free Radic Biol Med 53, 595-609.

[4] Dubois B, Epelbaum S, Santos A, Di Stefano F, Julian A, Michon A, Sarazin M, Hampel H (2013) Alzheimer disease: From biomarkers to diagnosis. Rev Neurol (Paris) 169, 744751.

[5] Juhász G, Földi I, Penke B (2011) Systems biology of Alzheimer's disease: How diverse molecular changes result in memory impairment in AD. Neurochem Int 58, 739-750.

[6] Humpel C (2011) Identifying and validating biomarkers for Alzheimer's disease. Trends Biotechnol 29, 26-32.

[7] Regeniter A, Kuhle J, Baumann T, Sollberger M, Herdener M, Kunze U, Camuso MC, Monsch AU (2012) Biomarkers of dementia: Comparison of electrochemiluminescence results and reference ranges with conventional ELISA. Methods 56, 494-499.

[8] Toledo JB, Brettschneider J, Grossman M, Arnold SE, Hu WT, Xie SX, Lee VM, Shaw LM, Trojanowski JQ (2012) CSF biomarkers cutoffs: The importance of coincident neuropathological diseases. Acta Neuropathol 124, 23-35.

[9] Federico A, Cardaioli E, Da Pozzo P, Formichi P, Gallus GN, Radi E (2012) Mitochondria, oxidative stress and neurodegeneration. J Neurol Sci 322, 254-262.
[10] McKhann G, Drachman D, Folstein M, Katzman R, Price D, Stadlan EM (1984) Clinical diagnosis of Alzheimer's disease: Report of the NINCDS-ADRDA work group under the auspices of department of Health and Human Services Task Force on Alzheimer's Disease. Neurology 34, 939-944.

[11] Delacourte A, Galasko D, Gauthier S, Jicha G, Meguro K, O’Brien J, Pasquier F, Robert P, Rossor M, Salloway S, Stern Y, Visser PJ, Scheltens P (2007) Research criteria for the diagnosis of Alzheimer's disease: Revising the NINCDS-ADRDA criteria. Lancet Neurol 6, 734-746.

[12] American Psychiatric Association. (1994) Diagnostic and Statistical Manual of Mental Disorders, IV. Text Revision (DSM-IV-TR).

[13] Rosen WG, Mohs RC, Davis KL (1984) A new rating scale for Alzheimer's disease. Am J Psychiatry 141, 1356-1364.

[14] Pákáski M, Drótos G, Janka Z, Kálmán J. (2012) Validation of the Hungarian version of Alzheimer's Disease Assessment Scale-cognitive subscale. Orv Hetil 153, 461-466.

[15] Folstein MF, Folstein SE, McHugh PR (1975) "Mini Mental State". A practical method for grading the cognitive state of patients for the clinician. J Psychiatr Res 12, 189-198.

[16] Janka Z, Somogyi A, Maglóczky E, Pákáski M, Kálmán J. (1988) Dementia screening by a short cognitive test. Orv Hetil 129, 2797-2800

[17] Kálmán J, Maglózky E, Janka Z (1995) Disturbed visuospatial orientation in the early stage of Alzheimer's dementia. Arch Gerontol Geriatr 21, 27-34.

[18] Beck AT, Ward CH, Mendelson M, Mock J, Erbaugh J (1961) An inventory for measuring depression. Arch Gen Psychiatry 4, 561-571.

[19] Kálmán J, Juhász A, Császár A, Kanka A, Maglóczky E, Bencsik K, Janka Z, Raskó I (1997) Apolipoprotein E allele frequencies in patients with late-onset sporadic Alzheimer's dementia in Hungary. Acta Neurol Scand 95, 56-59.

[20] Hamdane M, Delobel P, Sambo AV, Smet C, Bégard S, Violleau A, Landrieu I, Delacourte A, Lippens G, Flament S, Buée L (2003) Neurofibrillary degeneration of the Alzheimertype: An alternate pathway to neuronal apoptosis? Biochem Pharmacol 66, 1619-1625.

[21] Arendt T (2012) Cell cycle activation and aneuploid neurons in Alzheimer's disease. Mol Neurobiol 46, 125-135.

[22] Melberg A, Nennesmo I, Moslemi AR, Kollberg G, Luoma P, Suomalainen A, Holme E, Oldfors A (2005) Alzheimer pathology associated with POLG1 mutation, multiple mtDNA deletions, and APOE4/4: Premature ageing or just coincidence? Acta Neuropathol 110, 315-316.

[23] Podlesniy P, Figueiro-Silva J, Llado A, Antonell A, SanchezValle R, Alcolea D, Lleo A, Molinuevo JL, Serra N, Trullas $\mathrm{R}$ (2013) Low cerebrospinal fluid concentration of mitochondrial DNA in preclinical Alzheimer disease. Ann Neurol 74, 656-668.

[24] Edwards JA, Wang LG, Setlow RB, Kaminskas E (1989) O6methylguanine-DNA methyltransferase in lymphocytes of the elderly with and without Alzheimer's disease. Mutat Res 219, 267-272.

[25] Shimura H, Hattori N, Kubo Si, Mizuno Y, Asakawa S, Minoshima S, Shimizu N, Iwai K, Chiba T, Tanaka K, Suzuki T (2000) Familial Parkinson disease gene product, parkin, is a ubiquitin-protein ligase. Nat Genet 25, 302-305.

[26] Khandelwal PJ, Herman AM, Hoe HS, Rebeck GW, Moussa CE (2011) Parkin mediates beclin-dependent autophagic clearance of defective mitochondria and ubiquitinated Abeta in AD models. Hum Mol Genet 20, 2091-2102.

[27] Lonskaya I, Shekoyan AR, Hebron ML, Desforges N, Algarzae NK, Moussa CE (2013) Diminished parkin solubility and 
co-localization with intraneuronal amyloid- $\beta$ are associated with autophagic defects in Alzheimer's disease. J Alzheimers Dis 33, 231-247.

[28] Algarzae N, Hebron M, Miessau M, Moussa CE (2012) Parkin prevents cortical atrophy and $\mathrm{A} \beta$-induced alterations of brain metabolism: ${ }^{13} \mathrm{C}$ NMR and magnetic resonance imaging studies in AD models. Neuroscience 225, 22-34.

[29] Hong X, Liu J, Zhu G, Zhuang Y, Suo H, Wang P, Huang D, Xu J, Huang Y, Yu M, Bian M, Sheng Z, Fei J, Song H, Behnisch T, Huang F (2014) Parkin overexpression ameliorates hippocampal long-term potentiation and $\beta$-amyloid load in an Alzheimer's disease mouse model. Hum Mol Genet 23, 1056-1072.

[30] Kálmán J, McConathy W, Araoz C, Kása P, Lackó AG (2000) Apolipoprotein D in the aging brain and in Alzheimer's dementia. Neurol Res 22, 330-336.

[31] Belloir B, Kövari E, Surini-Demiri M, Savioz A (2001) Altered apolipoprotein D expression in the brain of patients with Alzheimer disease. J Neurosci Res 64, 61-69.

[32] Thomas EA, Laws SM, Sutcliffe JG, Harper C, Dean B, McClean C, Masters C, Lautenschlager N, Gandy SE, Martins RN (2003) Apolipoprotein D levels are elevated in prefrontal cortex of subjects with Alzheimer's disease: No relation to apolipoprotein E expression or genotype. Biol Psychiatry 54, 136-141.

[33] Terrisse L, Poirier J, Bertrand P, Merched A, Visvikis S, Siest G, Milne R, Rassart E (1998) Increased levels of apolipoprotein D in cerebrospinal fluid and hippocampus of Alzheimer's patients. J Neurochem 71, 1643-1650.

[34] Guo Q, Fu W, Xie J, Luo H, Sells SF, Geddes JW, Bondada V, Rangnekar VM, Mattson MP (1998) Par-4 is a mediator of neuronal degeneration associated with the pathogenesis of Alzheimer disease. Nat Med 4, 957-962.

[35] Perry G, Nunomura A, Smith MA (1998) A suicide note from Alzheimer disease neurons? Nat Med 4, 897-898.

[36] Xie J, Guo (2005) PAR-4 is involved in regulation of beta-secretase cleavage of the Alzheimer amyloid precursor protein. J Biol Chem 280, 13824-13832.

[37] Wang G, Dinkins M, He Q, Zhu G, Poirier C, Campbell A, Mayer-Proschel M, Bieberich E (2012) Astrocytes secrete exosomes enriched with proapoptotic ceramide and prostate apoptosis response 4 (PAR-4): Potential mechanism of apoptosis induction in Alzheimer disease. J Biol Chem 287, 21384-21395.

[38] Chaudhry P, Singh M, Parent S, Asselin E (2012) Prostate apoptosis response 4 (Par-4), a novel substrate of caspase-3 during apoptosis activation. Mol Cell Biol 32, 826-839.

[39] Rotonda J, Garcia-Calvo M, Bull HG, Geissler WM, McKeever BM, Willoughby CA, Thornberry NA, Becker JW (2001) The three-dimensional structure of human granzyme B compared to caspase-3, key mediators of cell death with cleavage specificity for aspartic acid in P1. Chem Biol 8 , 357-368.

[40] Kidd VJ, Lahti JM, Teitz T (2000) Proteolytic regulation of apoptosis. Semin Cell Dev Biol 11, 191-201.

[41] Chaitanya GV, Steven AJ, Babu PP (2010) PARP-1 cleavage fragments: Signatures of cell-death proteases in neurodegeneration. Cell Commun Signal 8, 31.

[42] Haile Y, Simmen KC, Pasichnyk D, Touret N, Simmen T, Lu JQ, Bleackley RC, Giuliani F (2011) Granule-derived granzyme B mediates the vulnerability of human neurons to $\mathrm{T}$ cell-induced neurotoxicity. J Immunol 187, 48614872.

[43] Patrick GN, Zukerberg L, Nikolic M, de la Monte S, Dikkes P, Tsai LH. (1999) Conversion of p35 to p25 deregulates Cdk5 activity and promotes neurodegeneration. Nature 402, 615622.

[44] Cruz JC, Kim D, Moy LY, Dobbin MM, Sun X, Bronson RT, Tsai LH (2006) p25/cyclin-dependent kinase 5 induces production and intraneuronal accumulation of amyloid beta in vivo. J Neurosci 26, 10536-10541.

[45] Wen Y, Yu WH, Maloney B, Bailey J, Ma J, Marie I, Maurin T, Wang L, Figueroa H, Herman M (2008) Transcriptional regulation of beta-secretase by $\mathrm{p} 25 / \mathrm{cdk} 5$ leads to enhanced amyloidogenic processing. Neuron 57, 680-690.

[46] Kanungo J, Zheng YL, Amin ND, Pant HC (2009) Targeting Cdk5 activity in neuronal degeneration and regeneration. Cell Mol Neurobiol 29, 1073-1080.

[47] Shukla V, Skuntz S, Pant HC (2012) Deregulated Cdk5 activity is involved in inducing Alzheimer's disease. Arch Med Res 43, 655-662.

[48] Lalioti V, Pulido D, Sandoval IV (2010) Cdk5, the multifunctional surveyor. Cell Cycle 9, 284-311.

[49] Van Troys M, Huyck L, Leyman S, Dhaese S, Vandekerkhove J, Ampe C (2008) Ins and outs of DF/cofilin activity and regulation. Eur J Cell Biol 87, 649-667.

[50] Sántha P, Pákáski M, Fazekas OC, Fodor EK, Kálmán S, Kálmán J Jr, Janka Z, Szabó G, Kálmán J (2012) Restraint stress in rats alters gene transcription and protein translation in the hippocampus. Neurochem Res 37, 958-964.

[51] Sadleir KR, Vassar R (2012) Cdk5 protein inhibition and $A \beta 42$ increase BACE1 protein level in primary neurons by a post-transcriptional mechanism: Implications of CDK5 as a therapeutic target for Alzheimer disease. J Biol Chem 287, 7224-7235.

[52] Tandon A, Yu H, Wang L, Rogaeva E, Sato C, Chishti MA, Kawarai T, Hasegawa H, Chen F, Davies P, Fraser PE, Westaway D, St George-Hyslop PH (2003) Brain levels of CDK5 activator p25 are not increased in Alzheimer or other neurodegenerative diseases with neurofibrillary tangles. J Neurochem 86, 572-581.

[53] Hodgkinson VC, Eaglea GL, Drewa PJ, Linda MJ, Cawkwella L (2010) Biomarkers of chemotherapy resistance in breast cancer identified by proteomics: Current status. Cancer Lett 294, 13-24.

[54] Bagnis A, Izzotti A, Centofanti M, Saccà SC (2012) Aqueous humor oxidative stress proteomic levels in primary open angle glaucoma. Exp Eye Res 103, 55-62.

[55] Izzotti A, Balansky R, D’Agostini F, Longobardi M, Cartiglia C, La Maestra S, Micale RT, Camoirano A, Ganchev G, Iltcheva M, Steele VE, De Flora S. (2013) Relationships between pulmonary microRNA and proteome profiles, systemic cytogenetic damage, and lung tumors in cigarette smoke-exposed mice treated with chemopreventive agents. Carcinogenesis 34 2322-9.

[56] Yuan X, Desiderio DM (2005) Proteomics analysis of human cerebrospinal fluid. J Chromatogr B Analyt Technol Biomed Life Sci 815, 179-189.

[57] Welinder C, Ekblad L. (2011) Coomassie staining as loading control in western blot analysis. J Proteome Res 10, 14161419

[58] Zellner M, Winkler W, Hayden H, Diestinger M, Eliasen M, Gesslbauer B, Miller I, Chang M, Kungl A, Roth E, Oehler R (2005) Quantitative validation of different protein precipitation methods in proteome analysis of blood platelets. Electrophoresis 26, 2481-2489.

[59] Hu Y, Malone JP, Fagan AM, Townsend RR, Holtzman DM (2005) Comparative proteomic analysis of intra- and interindividual variation in human cerebrospinal fluid. $\mathrm{Mol}$ Cell Proteomics 4, 2000-2009. 